\title{
Analysis of the Influence of Environmental Factors on Phytoplankton Using Structure Equation Model
}

\author{
Ran Liu' ${ }^{1, a}$, Wang Tian ${ }^{1, b}$ and Huayong Zhang ${ }^{1, c,{ }^{*}}$ \\ ${ }^{1}$ Research Center for Engineering Ecology and Nonlinear Science, North China Electric Power \\ University, Beijing 102206, China \\ azz_920320@163.com, btianwang@ncepu.edu.cn, cbjecology@gmail.com, *Corresponding author
}

Keywords: Environmental factors, Phytoplankton biomass, Structure equation modal, Relationship, Eutrophication.

Abstract. Human-driven eutrophication has caused great changes of phytoplankton community in many China lakes. As a result, the functioning of these lake ecosystems is threatened. In this research, field investigations and sampling were carried out in June 2011 and 2012 in Lake Qixinghu, a coal mining subsidence and heavy eutrophic lake. The influence of main environmental factors on phytoplankton community is analyzed using Structural Equation Modeling (SEM). According to the SEM result, water temperature (WT), dissolved oxygen (DO) and $\mathrm{pH}$ are the key factors influencing the density of phytoplankton, standardized partial regression coefficient were $-0.49,0.48$ and 0.40 . In addition, positive covariance terms existed between $\mathrm{DO}$ and $\mathrm{pH}, \mathrm{pH}$ and WT. Results in this research will be helpful in understanding the influencing factors of phytoplankton community in heavy eutrophic lakes and could be favor to make measures to improve water quality protect.

\section{Introduction}

Phytoplankton which had a wide distribution in the aquatic environment was the base of primary producers and food chains in aquatic environments [1]. It plays an important role in the energy flow and material circulation of ecosystems. The characteristics of phytoplankton community structure at taxonomic, abundance and biomass and the influence of chemical and biological factors on phytoplankton community had an instructive role in the change of environmental conditions [2-4]. Meanwhile, the change of environmental conditions also affects the community structure of phytoplankton directly or indirectly [5].

Nowadays, there are many researches about the influence of environmental factors on phytoplankton, but most of them employ traditional methods, including regression analysis (RA), principal component analysis (PCA), correlation analysis (CA), gray relational analysis (GRA), and so on. These methods had flaws in dealing with multivariable which cannot be analyzed at the same time $[6,7]$. Structural Equation Modeling (SEM), one of new generation of statistical methods, can address this problem well. It also allows for the inclusion of independent variables and dependent variables.

In this research, we use SEM to analyze the main influence factors of phytoplankton community in Lake Qixinghu, a coal mining subsidence and heavy eutrophic lake, based on field investigations and sampling in June 2011 and 2012. The purpose of this research is to provide reasonable suggestions for water environment protection of Lake Qixinghu.

\section{Materials and Methods}

Study Area: Qixinghu Lake is located in Tengzhou City, Shandong Province, and it is formed on the coal mine subsidence area (Figure 1). With a water storage capacity of $720,000 \mathrm{~m}^{3}$, the area of Lake Qixinghu is $0.33 \mathrm{~km}^{2}$ and the average depth of it is $2.0 \mathrm{~m}$. The lake climate is a typical warm temperate monsoon climate .The average annual temperature is $10.66-30.88{ }^{\circ} \mathrm{C}$ and the average annual rainfall is 550 to $720 \mathrm{~mm}$. It is noteworthy that most of the rainy season appears in the summer. In addition, Qixinghu Lake has two water inlets, with a large amount of nitrogen and phosphorus, which induce 
the eutrophication of Qixinghu Lake. So, it is very necessary to do research on the aquatic environment of Qixinghu Lake.

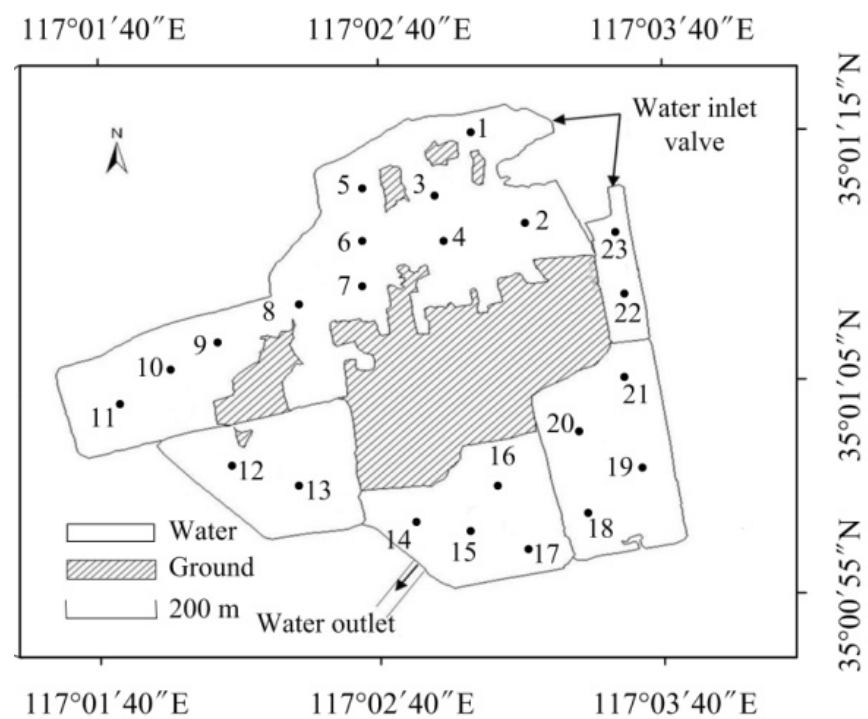

Fig .1 The location of Lake Qixinghu and the sample sites.

Sampling and Measurements: In this research, field investigations and sampling were carried out in June 2011 and 2012 in Lake Qixinghu. In the lake, we set 16 sampling sites (Fig. 1). During the sampling periods, samples were taken during 10 o'clock in the morning and 2 o'clock in the afternoon, respectively, with the same sampling points.

Water temperature (WT), dissolved oxygen (DO) and $\mathrm{pH}$ were measured in situ at 16 sampling sites using YSI Professional Plus (YSI Incorporated, Yellow Springs, OH, USA). Using a Tygon tube water sampler, water quality samples were collected at 0.50 meters below the water surface. Store the samples in acid-cleaned glass bottles at $4{ }^{\circ} \mathrm{C}$, and then filter with a $0.45 \mu \mathrm{m}$ acetate to filter. The concentration of $\mathrm{TN}$ was determined by potassium persulfate oxidation-UV spectrophotometry. Ammonia nitrogen $\left(\mathrm{NH}_{4}{ }^{+}-\mathrm{N}\right)$ was measured using Nessler reagent spectrophotometry. And the content of TP was determined by Mo-Sb spectrophotometry.

Statistical Analyses: In this research, Structural Equation Modeling (SEM) was used to study the relationship between phytoplankton and environmental factors. SEM consists of five steps, included model specification, model identification, model estimation, testing model fit and model modification. Amos 22.0 software was used to conduct structural equation modeling of species and environmental data. It should be noted that the data of phytoplankton density was transformed by $\lg (\mathrm{x}+1)$.

\section{Results}

Model analyses: In the first step of the analyses, we used SEM to quantify the relationship between phytoplankton and environmental factors. The initial model included 7 variables which had collect data from field sampling (Fig. 2). According to $t$-principle, when the number of model equations is greater than the number of variables, the initial model can be identified.

Beginning with the initial structural equation model (Fig. 2), we used the Amos 22.0 to parameterize the relationship between phytoplankton and environmental factors. We improve model fitness by $t$-principle and modification indices of Amos. Specifically, we remove the insignificant variables by $t$-principle at first $(\mathrm{p}>0.05)$ and then modified model by modification indices of Amos, until there are no insignificant variables indices advice. We used $\chi^{2}$-statistic to assess the overall significance of model fits to data ( $\mathrm{p}>0.05$ ). And also use expected cross-validation (ECVI), root mean square error of approximation (RMSEA), goodness-of-fit index (GFI), normed fit index (NFI), comparative fit index (CFI) and Akaike information criteria (AIC) to evaluate the model fitness [8]. 


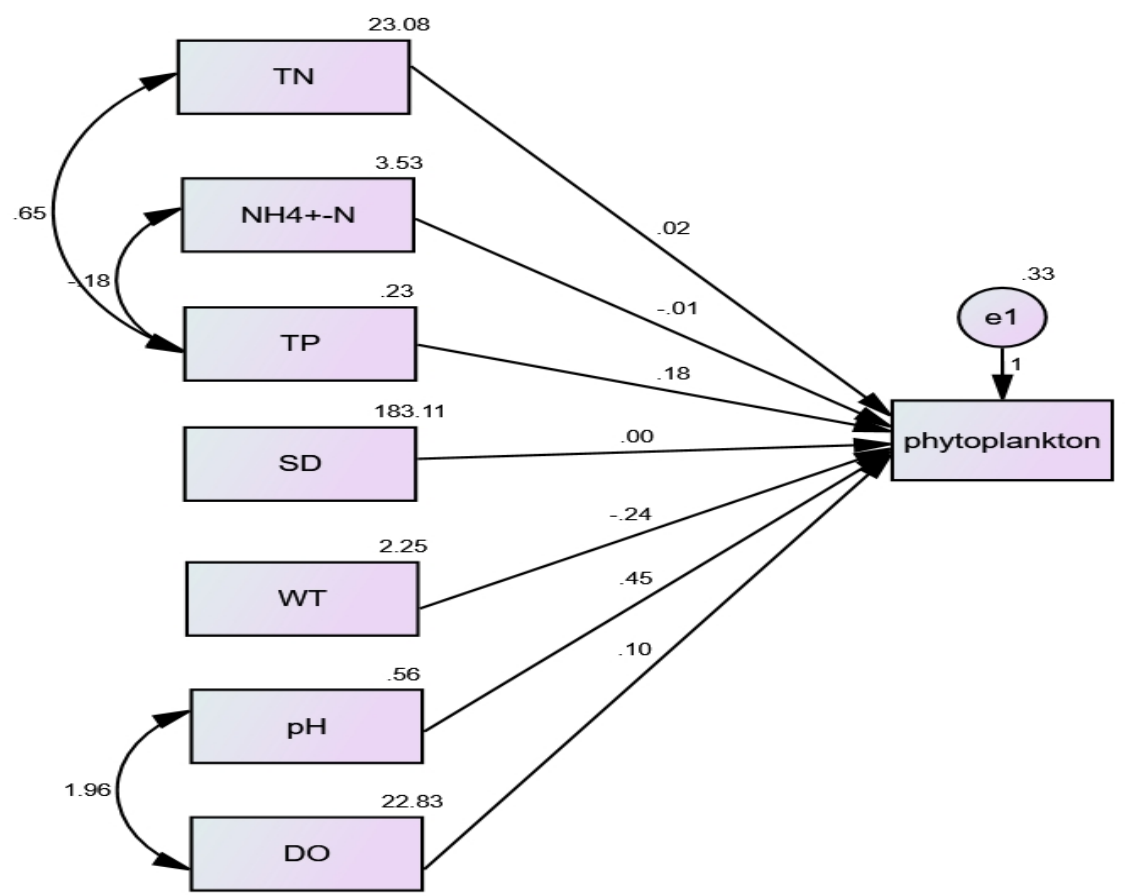

Fig. 2 The initial model with path coefficient

Model modification: In the initial model, because the factor loading of $\mathrm{SD}, \mathrm{NH}_{4}{ }^{+}-\mathrm{N}, \mathrm{TP}$ and $\mathrm{TN}$ were insignificant, we decided to remove them (Table. 1). After that, the parameters of the modified model which called M1 all passed the significance test (Table. 1). And then we increase the path between $\mathrm{pH}$ and WT by modification indices of Amos. The modification model called M2.

Table 1 The fitness index of phytoplankton

\begin{tabular}{|c|c|c|c|c|c|c|c|}
\hline \multirow{2}{*}{$\begin{array}{l}\text { Goodness-of } \\
\text {-fit indices } \\
\text { standard }\end{array}$} & $\chi^{2}$ & RMSEA & ECVI & GFI & NFI & CFI & AIC \\
\hline & $p>0.05$ & $<0.05$ & $\begin{array}{c}\text { more } \\
\text { smaller }\end{array}$ & $>0.9$ & $>0.9$ & $>0.9$ & $\begin{array}{c}\text { more } \\
\text { smaller }\end{array}$ \\
\hline Initial model & $44.47 * * *$ & 0.22 & 2.60 & 0.75 & 0.46 & 0.52 & 80.47 \\
\hline M1 & $14.73 * * *$ & 0.45 & 0.99 & 0.84 & 0.69 & 0.69 & 30.73 \\
\hline M2 & $5.14 *$ & 0.37 & 0.75 & 0.93 & 0.89 & 0.90 & 23.14 \\
\hline
\end{tabular}

***: $p<0.001$ level;*: $p<0.05$ level

According to the above mentioned evaluation criteria of fitness, we can see that M2 is the best-fitting model with the smallest $\chi^{2}$, ECVI and AIC and the highest GFI, NFI, CFI. Although RMSEA of M2 is higher than the initial model and $\chi^{2}$, NFI, CFI cannot reach the ideal standard. It is still the most suitable structural equation modeling during commissioning (Table. 1).



Fig. 3 The modification model M2 with standardized coefficient. 
Model results: The best-fitting model included just three explanatory variables - DO, $\mathrm{pH}$, and WT (Fig. 3). The strongest predictor of phytoplankton density in this final model was $\mathrm{pH}$ with a standardized partial regression coefficient of $0.51(\mathrm{p}<0.05)$. The standardized partial regression coefficient from WT to phytoplankton density was $-0.29(\mathrm{p}<0.05)$, and the standardized partial regression coefficient from DO to phytoplankton density was $0.09(\mathrm{p}<0.05)$. Additional positive covariance terms existed between DO and $\mathrm{pH}$ and $\mathrm{pH}$ and WT. All of them were statistically significant $(p<0.05)$, therefore, the best-fitting model including $\mathrm{DO}, \mathrm{pH}$, and $\mathrm{WT}$.

WT is the most direct environmental factor that affects the growth of phytoplankton [9-11]. In general, there is a positive correlation between light and phytoplankton density, such as Deng [12] found that the phytoplankton density is positively correlated with WT on a research about the phytoplankton in Lake Yeyahu. In this research, the negative correlation between temperature and phytoplankton density was mainly due to data anomalies that the phytoplankton cell numbers at 4,8 and 15 sites were too high in 2011.

\section{Conclusions}

According to the results of SEM, WT, DO and $\mathrm{pH}$ are the key factors influencing the density of phytoplankton, standardized partial regression coefficient were $-0.49,0.48$ and 0.40 , respectively. In addition, positive covariance terms existed between $\mathrm{DO}$ and $\mathrm{pH}, \mathrm{pH}$ and $\mathrm{WT}$. All of them were statistically significant $(p<0.05)$. We hope that results in this research will be helpful in understanding the influencing factors of phytoplankton community in heavy eutrophic lakes and could be favor to make measures to improve water quality protect.

\section{Acknowledgments}

This work was financially supported by the National Special Water Programs (No. 2015ZX07204-007).

\section{Reference}

[1] A. J. Horne and C. R: Limnology. McGraw-Hill, (1983), p. 1049-1061.

[2] L. Håkanson and V. V. Boulion: Ecological Modelling, Vol. 165 (2003), p. 285-301.

[3] C. Gameiro, P. Cartaxana and V. Brotas: Estuarine Coastal \& Shelf Science, Vol. 75 (2007), p. 21-34.

[4] G. B. Arhonditsis, M. Winder, M. T. Brett, et al: Water Research, Vol. 38 (2004), p. 4013-4027.

[5] L. Lepistö, A. L. Holopainen and H. Vuoristo. Limnologica, Vol. 34 (2004), p. 236-248.

[6] K. A. Bollen : New York New York John Wiley \& Sons, Vol. 35 (1989), p. 289-308.

[7] R. B. Kline : Journal of the American Statistical Association, Vol. 101 (2010).

[8] E. K. Zimmerman, B. J. Cardinale: Oikos, Vol. 123 (2014), p. 267-278.

[9] J. Mayer, M. T. Doukulil, M. Salbrechter, et al: Hydrobiologia, Vol. 342-343 (1997), p.165-175.

[10] Y. Zhang, E. E. Prepas: Canadian Journal of Fisheries \& Aquatic Sciences, Vol. 53 (2011), p. 621-633.

[11] R. W. Koch, D. L. Guelda, P. A. Bukaveckas: Aquatic Ecology, Vol. 38 (2004), p. 17-26.

[12] W. L. DENG, J. P. LIU, X. X. WANG, et al: Wetland Science, Vol. 11 (2013), p. 27-31. 